\title{
Los trazos de Mafalda. Notas sobre intelectuales, liberal- consenvadurismo y derechas en la Argentina desde la Historia Político-Intelectual
}

\author{
Mafalda's draws. Notes on intellectuals, liberal-conservatism and rights in \\ Argentina from political-intellectual history
}

\author{
Martín Vicente \\ vicentemartin28@gmail.com \\ CONICET - Universidad Nacional del Centro \\ de la Provincia de Buenos Aires - Red de Estudios \\ Interdisciplinarios sobre Derechas, Argentina
}

Cita sugerida: Vicente, M. (2021). Los trazos de Mafalda. Notas sobre intelectuales, liberalconservadurismo y derechas en la Argentina desde la Historia Político-Intelectual. Sociohistórica, 47, e132. https://doi.org/10.24215/18521606e132
Resumen: El presente texto propone un recorrido sobre problemáticas teóricas, metodológicas y analíticas de Historia Político-Intelectual para la discusión acerca de los intelectuales liberal-conservadores y las derechas en la Argentina. Se ordena en cuatro segmentos: una introducción al tema, un abordaje a la Historia Político-Intelectual, una mirada sobre tiempo, espacio y categorías, y una nota final a modo de conclusión. En él se discute, centralmente, a la luz de un proyecto de investigación doctoral y de posteriores indagaciones en temas vinculados a él.

Palabras clave: Historia Político-Intelectual, Liberalconservadurismo, Intelectuales, Derechas.

Abstract: The present text proposes a tour of theoretical, methodological and analytical problems of Political-Intellectual History for the discussion on liberal-conservative intellectuals and rights in Argentina. It is arranged in four segments: an introduction to the topic, an approach to Political-Intellectual History, a look at time, space and categories and a final note as a conclusion. It is discussed centrally in light of a doctoral research project and subsequent inquiries on related topics.

Keywords: Political-Intellectual History, LiberalConservatism, Intellectual, Rights.
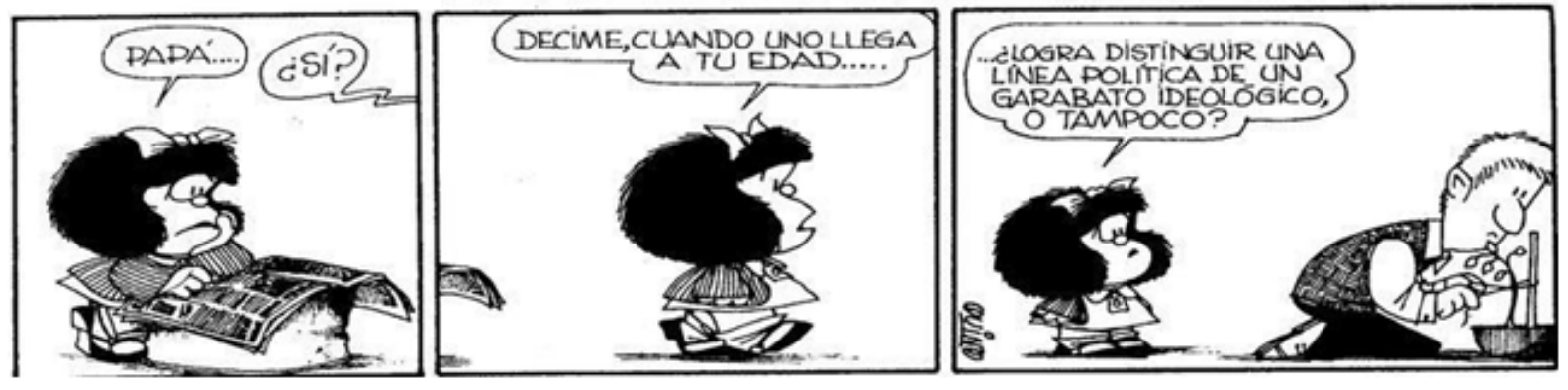


\section{UNA NOTA COMO INTRODUCCIÓN}

En una tira de la historieta Mafalda, publicada sobre el final de la década de 1960, la niña protagonista se acercaba a su padre con un diario en la mano y le preguntaba: "Papá, cuando uno llega a tu edad, ¿logra distinguir una línea política de un garabato ideológico, o tampoco?”. El rostro extrañado del adulto ante la pregunta de su hija parecía anticipar el que encontré una y otra vez entre oyentes de mi proyecto doctoral, hace ya una década: estudiar a los intelectuales liberal-conservadores entre 1955 y 1983. En efecto, ante los intelectuales liberal-conservadores, el primer gesto era de extrañeza, cuando no de estupefacción o incredulidad: liberales que apoyaron regímenes autoritarios, conservadores modernizantes, católicos que se separaron de la Iglesia, demócratas que entendieron la democracia de masas como un problema...Una aproximación primaria al objeto resaltaba, efectivamente, lo que en principio pueden parecer contradicciones, posiciones extravagantes o meras formas retóricas. Si la sorpresa de mis interlocutores por fuera del espacio académico no me resultaba extraña (a fin de cuentas, yo estudiaba "fachos"), la confusión que muchas veces producía el tema entre colegas (y que aún, por momentos, sigue produciendo) me llamaba la atención especialmente: alguna vez me señalaron que llamar "liberales" a esos "conservadores" o "derechistas" era "un elogio"; otras, me indicaron de modo pedagógico que "liberalismo y conservadurismo son antónimos" y que en todo caso se trataría de "conservadores disfrazados de liberales" (un autoasumido conservador, por su parte, me dijo que se trataba de "conservadores que quieren un liberalismo posible"); en una tercera explicación, no faltaron quienes enfatizaron que se trataba, antes bien, de "liberales en lo económico, conservadores en lo político" (como gustaba autodescribirse el diario La Nación antes de retomar la categorización republicana en los últimos años).

Ante estas explicaciones, se imponía un señalamiento por dos vías, recorriendo los debates políticos de coyuntura y la historia de las investigaciones sobre las derechas argentinas. Por un lado, las aproximaciones al liberalismo-conservador aparecían teñidas por lo coyuntural, donde las derechas argentinas hegemonizadas por el neoliberalismo luego de 1983 giraban hacia una retórica republicana como modo de enfrentar lo que denominaban "populismo" kirchnerista; por el otro, efectivamente, para la época los estudios sobre las derechas argentinas del siglo XX se habían centrado primeramente en las derechas nacionalistas de la primera parte del siglo y el neoliberalismo de fines de la centuria, amén de los estudios sobre las tramas golpistas y autoritarias. En ese panorama, preguntarse por el liberalismo-conservador era hacerlo por una línea que había sido poderosa intelectual y políticamente, pero desatendida por los analistas y que muchas veces aparecía como fórmula pero no como definición. Resumiendo, el liberal-conservadurismo o liberalismoconservador posee una historia que se inicia con voces como las de Alexis de Tocqueville y los doctrinarios en Francia, Edmund Burke en Inglaterra y los federalistas en los Estados Unidos, que antepusieron una mirada ordenancista, temerosa de las masas y el cambio violento, a los criterios liberales previos de corte ecuménico, universalista e igualitario, en gran parte como consecuencia de la Revolución Francesa primero y de las revoluciones europeas de 1848 luego. Contra ellas, propondrá modelos moderantistas basados en las enseñanzas de las tradiciones, el respeto a los valores humanistas clásicos y modernos y una noción acotada del ideario republicano, centrada en la racionalidad de un modelo democrático elitista y de baja intensidad. Estas posiciones, que impactaron en la Generación de 1837 en nuestro país y dieron forma liberalconservadora al romanticismo de los autores de la Joven Generación, signaron la tradición liberal argentina hasta la segunda posguerra, cuando, en medio de un proceso de "crisis y transformación", como lo denominó Jorge Nallim (2014), emergió la generación de jóvenes intelectuales que hegemonizó el liberalismo argentino en el posperonismo y mantuvo ese sitio por casi 30 años, por medio de una articulación de aquellas bases con la perspectiva elitista de José Ortega y Gasset, una lectura por derecha de la renovación humanista católica francesa y una asunción atenuada de la renovación neoliberal y neoconservadora.

Por lo antedicho, un abordaje en profundidad sobre estos intelectuales implicaba, en los lineamientos que me había planteado, una doble operación: en primer lugar, reposicionar el sitio de estos actores desde la 
noción ideológica; en segundo término, estudiar sus intervenciones intelectuales desde los propios planos que organizaban temáticamente las lecturas y argumentaciones de estos actores. Dicho modo de acercarse al objeto, entonces, significó oscilar entre las modalidades de construcción del lugar de nuestros actores y el balance de tal construcción en distintas líneas de sentido (el espacio académico, el de las polémicas intelectuales, sus cruces con el mundo de la política o el periodismo, la relación de agendas locales e internacionales, entre otras). En esa dinámica se forjó el sitio de los intelectuales liberal-conservadores en aquellos años, en gran parte $s u$ tiempo: el momento en que ascendieron al espacio público, hegemonizaron el liberalismo argentino, las derechas locales en general y, finalmente, comenzaron su ocaso tras el fracaso de su proyecto refundacional vinculado a la última dictadura.

El trabajo sobre el amplio universo liberal argentino fue mi primer objeto de investigación de largo aliento, pero cerró un trayecto personal más amplio, ya que estuvo precedido por dos investigaciones formativas. Primero, mi trabajo de grado, en el que abordé la Revista Argentina de Ciencias Politicas y el reformismoliberal del Centenario, y luego mi tesis de posgrado sobre las relaciones entre los intelectuales liberal-conservadores y la última dictadura. En el primero de los textos, buscaba desmontar la idea del liberalismo argentino del siglo XX como un ideario siempre escorado en la derecha de la geografía política local (evidente resabio de los debates de la época, promediando la primera década de los 2000), al tiempo que marcar el paso desde el reformismo a la oposición a la democracia de masas en un referente como aquella revista dirigida por Rodolfo Rivarola. En mi trabajo de Maestría, en cambio, había abordado las figuras del filósofo Jorge Luis García Venturini, el abogado Jaime Perriaux y el economista Ricardo Zinn desde un doble movimiento: primero, exponer cómo las investigaciones sobre intelectuales entre 1955 y 1983 habían dejado a un lado a las derechas liberales y cómo recuperar sus voces aportaba a una comprensión del proyecto refundacional procesista. A la hora de ampliar el foco, para mi tesis de Doctorado opté por tomar el marco 1955-1983 completo y analizar las figuras e ideas de un abanico amplio de actores: Álvaro Alsogaray, Alberto Benegas Lynch, Germán Bidart Campos, Horacio García Belsunce, Jorge Luis García Venturini, Mariano Grondona, Juan Segundo Linares Quintana, Mario Justo López, José Alfredo Martínez de Hoz, Víctor Massuh, Jaime Perriaux, Ambrosio Romero Carranza, Carlos Sánchez Sañudo, Ricardo Zinn. Ello me permitía operar con un espacio heterogéneo de actores, pero ligados por más vínculos que el ideológico. Una vez presentado este grueso de mi trayectoria, me gustaría reparar en una serie de puntos ligados a mi trabajo como investigador, centrados en esa investigación doctoral y los proyectos posteriores que se abrieron a partir de ella: el trabajo sobre el grupo político-intelectual de la revista Orden Cristiano (editada entre 1941 y 1948) y el estudio sobre la recepción de los debates aceca del totalitarismo en la Argentina.

\section{Una Nota sobre la Historia Político-Intelectual: el enfoque y el obJeto "INTELECTUALES"}

Mis trabajos se enmarcan en la Historia Político-Intelectual entendida en un sentido, por un lado, amplio, al tiempo que más acotado en otro eje. En el primero de los enfoques, entiendo la concepción y la metodología de la Historia Político-Intelectual como orientada por la pauta general de la escuela de Cambridge, "textos en contexto", comprendiendo allí la necesidad de enlazar las dimensiones de los actores, sus producciones y la serie de contextos en los que esas intervenciones intelectuales operan de modo directo (es decir, abiertamente tematizado por ellos) o indirecto (aquello no explicitado ni connotado). Tal como ha propuesto Françoise Dosse, entiendo la productividad de las relaciones entre la Historia Intelectual y la Historia de los Intelectuales antes como un espacio heterogéneo que como un eje disciplinar encorsetado (Dosse, 2007). En ese sentido, busco que mi producción pueda establecer una relación central entre las preguntas de la Teoría Política y la Historia Cultural y los postulados de la Historia y la Sociología de los Intelectuales. Me interesa mayormente analizar cómo las ideologías son puestas en acción por actores, grupos o en experiencias en marcos históricos determinados y en diálogo con 
contextos que se entrecruzan o superponen. Ello implica, en el foco de mis investigaciones, una relación historiográfica entre la Historia Política más específica y los sentidos más amplios de la Historia Cultural, con sus respectivas diversas perspectivas y en torno a estados de producción determinados por cada uno de los temas que poseen peso sobre las múltiples aristas que presentan las investigaciones de este estilo.

En el segundo de los ejes, el de tenor más acotado, comprendo la Historia Político-Intelectual, en el enfoque que me compete, como inseparable de determinadas líneas rectoras: trabajar en torno a idearios, actores intelectuales y temas capaces de representar tanto condiciones estructurales como aspectos particulares. En ese sentido, descarto en mis trabajos tanto el sesgo generalista, por inespecífico, como la lectura ultraespecífica, por su escasa representatividad. Al tiempo que, más allá de mi inscripción dentro de los cánones teórico-metodológicos de la Historia Intelectual, mi concepción sobre ciertas pautas ya clásicas es escéptica, como ocurre con una cuestión que ha sido ampliamente debatida por los grandes referentes de esta tendencia: la llamada lectura "intencionalista", que propone determinar la intención con la cual un autor ha escrito un texto y que ha atravesado tanto a los teóricos que se han dedicado a la historia de la Filosofía Política como a los propios representantes de la Historia Intelectual (Skinner, 2007).

Una vez presentados los puntos previos, aparece un tercer factor: la diferencia de enfoques generales entre las grandes escuelas de análisis que, en términos generales, podemos categorizar dentro de la Historia Intelectual. Descartada la visión de la más tradicional Historia de las Ideas, sobre la cual comparto la crítica básica que han realizado los referentes de la Historia Intelectual al tiempo que reconozco sus notables (sí que limitados) aportes, creo necesario detenerme en dos ítems. El primero de ellos es el problema de las interpretaciones a posteriori de las obras: en ellas, importa, antes que una lectura contextual, una enfocada en los usos para el presente. Esta diferencia, que se puede expresar de modo sucinto como lo hizo Andrés Rosler en la fórmula-pregunta “¿Oxford vs. Cambridge?”, permite versiones intermedias (Rosler, 2016). Creo que este es un punto de atención que permite unir las inquietudes sobre los usos de una obra con una lectura no ya "verdadera" sino, antes bien, una interpretación sobre las diversas interpretaciones canónicas. La idea del descentramiento o el estiramiento conceptual es un aporte de enfoque que considero sumamente importante para pautas investigativas como las que propongo: en efecto, antes que preocuparnos por interpretaciones "verdaderas", interesa hacerlo por usos. El segundo ítem es el uso práctico de ese enfoque: volviendo a mis trabajos de investigación, busco la misma pauta teórico-metodológica de fondo como configuradora. Los distintos objetos, actores y temas configuran diferencias en el enfoque, como podrá notar quien conozca a los diversos grupos; sin embargo, más allá de compartir las líneas de enfoque generales, hay una serie de temas en común que atraviesan los distintos proyectos: las relaciones entre situaciones internacionales, regionales y nacionales, en especial el impacto de grandes sucesos políticos; las transformaciones teóricas y los debates ideológicos, del mundo a lo local; los centros, límites y relaciones de la tan evanescente como presente tradición liberal-republicana; las sucesivas conexiones del antifascismo, antiperonismo y anticomunismo. En ese sentido, hay una continuidad entre los temas: por un lado, el trabajo sobre el liberal-conservadurismo me abrió una pregunta central por el rol de la renovación humanista, que me llevó a Orden Cristiano tras charlas con investigadores como Miranda Lida y José Zanca. La investigación sobre la recepción y usos del totalitarismo en el espacio antitotalitario, por su parte, apareció como una consecución lógica del tránsito previo: tanto liberales como católicos democráticos habían hecho de sus posiciones antitotalitarias un factor central de sus posicionamientos, a los que sumé la perspectiva de liberal-progresistas. Sin embargo, la notable ausencia del tema como articulador central de trabajos en nuestro ámbito académico muestra que las problemáticas del eje totalitarismo-antitotalitarismo lejos estuvieron de tener entre nosotros el peso de otros clivajes.

El objeto general de mis investigaciones han sido las relaciones entre intelectuales y política o, para decirlo de manera más detallada, de qué manera las ideologías actúan en las construcciones político-intelectuales expresadas por diversos protagonistas de la intelectualidad argentina. Lo que me interesa centralmente de los intelectuales es un triple carácter: ser voceros ideológicos, participar de diversos espacios más allá del 
propio universo intelectual y estar marcados por un debate político que al tiempo es interno y externo a su propio espacio primario. Como marqué previamente, mi enfoque se basa en analizar las diversas maneras en que las ideologías se han puesto en acto (conceptual, narrativo, performativo, polémico) desde las intervenciones intelectuales, inquietud que ha recorrido mis tres proyectos de investigación. Aquí encuentro que la centralidad de los actores intelectuales implica una serie de puntos: se trata de figuras intelectuales en las que aparece la marca fundante del caso Dreyfus; es decir, la concepción del intelectual como un sujeto político que interviene en la esfera pública de modo polémico desde una concepción legitimista de su capital cultural, entendido este término en el sentido restrictivo matricial impulsado desde aquel affaire (Charle, 2009). Esos temas implicaron abordar, en torno a ese modelo, figuras intelectuales muy diferentes. Me detengo a continuación, brevemente, en aspectos específicos de cada investigación.

Los intelectuales liberal-conservadores implicaron un trabajo sobre la categoría de intelectual que partía de determinadas complejidades: por un lado, el universo heterogéneo de actores seleccionado buscaba tanto representar las líneas maestras de este espacio (profesiones, trayectorias político-intelectuales, preeminencia al interior del universo) como expresarlo desde una perspectiva que, al desagregarlo, mostrara cómo esa heterogeneidad relativa implicaba también la construcción de líneas de homogeneidad. En efecto, el ciclo cubierto en ese trabajo mostraba una serie de características que ligaban a esta constelación de actores con otros grupos intelectuales, especialmente al interior de la amplia constelación de familias de derecha, al tiempo que la dotaban de especificidad: la primacía de los abogados como formación de base; el impacto de la renovación neoliberal primeramente entre economistas; las complejas relaciones entre el ensayismo y las Ciencias Sociales y entre el discurso doctrinario y las intervenciones polémicas, entre otros. En el momento en que me centré en esos intelectuales, los trabajos eran pocos y heterogéneos, pero en la última década las perspectivas sobre la tradición liberal se han fortalecido y los enfoques, refinado.

Con respecto al grupo de Orden Cristiano, los primeros trabajos que se referían a este conjunto ubicaban a estos actores en el catolicismo democrático y/o en el catolicismo liberal, si bien no los abordaban en sentido denso pues trabajaban sobre el universo católico en términos macro. En ese sentido, los estudios de José Zanca han marcado cómo una serie de pautas, como el humanismo y el personalismo, poseían preeminencia en Orden Cristiano por encima del catolicismo liberal pero cómo, al mismo tiempo, el liberalismo es un punto a considerar para abordar el quincenario (Zanca, 2013a, 2013b). Por otro lado, Nallim ha hecho un uso muy productivo del diálogo que estos católicos presentaron con el universo liberal, en especial desde un eje que ha interesado a ambos: el marco antifascista (Nallim, 2014). Allí, mis trabajos se interesaron por entender las relaciones heterogéneas entre catolicismo, liberalismo y democracia. Al mismo tiempo, aparecía en los actores del quincenario una pauta que los hacía comprensibles como intelectuales militantes, activistas: un rostro que los colocaba en las dinámicas polémicas del antifascismo.

Con respecto a las recepciones y usos del totalitarismo en la Argentina, se trata de un trabajo aún en desarrollo, sobre el que me interesa destacar tres cuestiones. En primer lugar, las relaciones dinámicas entre antifascismo, antipopulismo y anticomunismo que las posiciones anti-totalitarias permitieron (y, en vistas de ciertos discursos que atraviesan a las derechas actuales, aún permiten); en segundo término, que la centralidad de los intelectuales en mis investigaciones previas se correspondía con una primacía de estos actores que, en el tema del totalitarismo, muestra una presencia más consolidada, por ejemplo, de los partidos políticos; en un tercer eje, me interesa destacar la potencialidad de este tema no sólo como articulador de los previos (el mismo proyecto los rescata pero antes por relaciones específicas que por la construcción de una o varias lógicas generales) sino también como nexo entre el plano internacional y el nacional que incluya una serie de dinámicas determinantes, al tiempo que para especificar cómo la temática del totalitarismo permitía reescribir la historia nacional a la luz de las transformaciones conceptuales, los debates políticos y las polémicas específicas.

En términos generales, en mis artículos antepongo el debate teórico-conceptual al metodológico: prefiero que la metodología aparezca configurando la forma y el proceder de los trabajos, antes que en un debate 
explícito sobre el enfoque, salvo que se trate de un trabajo que busque específicamente exponer problemas, estrategias o resoluciones metodológicas. Esta centralidad de lo teórico-conceptual, sin embargo, implica (por las peculiaridades de mis temas y enfoques) abordar una serie de términos que en ciertas de sus pautas podrían implicar debates metodológicos. Me centro en un ejemplo de cariz estructural, como es la noción de "campo intelectual". Esta herramienta, propia del trabajo sociológico de Pierre Bourdieu (Bourdieu, 1999; cf. Lahire, 2005), ha sido utilizada de modos que deforman la lógica rectora de su construcción original, pero muchas veces sin incurrir en las reformulaciones conceptuales y metodológicas necesarias: en ese sentido, asistimos a diversos trabajos que proponen la existencia de un campo intelectual en etapas cuando la institucionalización necesaria para su conformación estaba imposibilitada por las circunstancias políticas y cuando una serie de límites (como la censura o las exoneraciones universitarias) imposibilitaban el desarrollo relativamente autónomo del "espacio-campo", el cual, además, ya no aparecía determinado por la lógica de vinculación al campo económico (condición central para la idea de Bourdieu, finalmente un sociólogo marxista clásico en ese sentido) sino a otros propios de las instituciones político-legales.

La preeminencia organizativa de los textos con los cuales trabajo se da por diversas selecciones de autores, textos y temas que atraviesan los espacios de diálogo de mis investigaciones, entre la producción de carácter teórico-conceptual, la metodológica y los estudios de caso. En ese sentido, me interesan centralmente las investigaciones que logran dar cuenta de la complejidad de relaciones entre historia, política y mundos socio-culturales desde perspectivas con un fuerte anclaje teórico-conceptual que puedan ofrecer herramientas metodológicas antes por medio del desarrollo narrativo que por medio de debates metodológicos en sí mismos. Para ponerlo en dos ejemplos y luego retomar el argumento, cuando comencé mi trabajo doctoral Olga Echeverría (2009) publicó un libro en el que mostraba que la categorización de "nacionalistas" que se daba clásicamente a una serie de intelectuales que fueron referentes desde fines de los años 20 hasta el ciclo peronista era insuficiente, puesto que el nacionalismo tuvo en aquellos años inflexiones diversas, y que lo que caracterizaba las posiciones de estos autores era una concepción de derecha autoritaria del nacionalismo. Al mismo tiempo, logró enfatizar la serie de líneas que unían a esos actores con la tradición liberal-conservadora, más allá de la procedencia social de los personajes considerados; un giro complejo, dadas las críticas a la cultura liberal y al sistema político-legal originado por ella que recorrieron intelectuales como Leopoldo Lugones o los hermanos Julio y Rodolfo Irazusta, y que eran el énfasis de otros investigadores, como David Rock (1993) o Alberto Spektorowsky (2011). En un tercer aporte, mostró cómo el golpe de Estado de 1930 los tuvo antes como intelectuales decepcionados que como exponentes de la lógica uriburista. Más allá de los planteos teórico-metodológicos que la historiadora propuso en su trabajo, la exposición más acabada de ese triple aporte central radica en cómo lo plasmó en su narrativa: para decirlo de otro modo, las mismas conclusiones podrían haberse logrado con una refutación metodológica de los trabajos previos (algo que se desprende de los propios aportes de Echeverría a lo largo del texto, que también los utiliza como insumos); más interesante, sin embargo, es el proceder que se lleva a cabo a lo largo de la obra, mostrando la construcción interna y las diversas relaciones contextuales que explican esos diagnósticos. Por otro lado, más recientemente Adriana Petra (2018) articuló los debates internos de la intelectualidad comunista argentina con una serie de pautas internacionales y regionales, mostró las diversas líneas en las que esos intelectuales se alejaban de las lógicas partidarias y puso en claro las sucesivas tramas posicionales entre los años 30 y los 60 . La investigación de Petra muestra un equilibrio entre la exposición de las problemáticas globales (algo central para un ideario internacionalista), su recepción en el país y cómo ello impactó en un partido y un espacio de intelectuales que, muestra su investigación, lejos estuvieron de tener una relación vertical con lo emanado desde la Madre Rusia. Por el contrario, la autora plasma cuán compleja fue esa relación y cuánto más similares eran estos intelectuales en sus inquietudes a otras líneas de la intelectualidad local, lo cual hundía sus raíces en el antifascismo y en el "momento liberal" de una cultura política que luego abominó del liberalismo (cf. Pasolini, 2013). 
Estos dos trabajos, a primera vista, parecieran conectar con puntos menores de mis investigaciones: las derechas nacionalistas bien pueden leerse desde sus vínculos y diferencias con las liberales, la pertenencia de los comunistas al antifascismo (y luego, en parte y no en bloque, al antiperonismo: también allí Petra deshace miradas previas) permitiría un diálogo con liberales, católicos democráticos y antitotalitarios. Sin embargo, el trabajo de Echeverría me permitió pensar una serie de pautas para leer a los intelectuales liberalconservadores: primero, las relaciones de los intelectuales entre sus proyectos políticos (específicamente, los ligados a golpes de Estado y las miradas refundacionales) y los efectivos resultados de experiencias políticas: allí aparecían la distancia entre el refundacionalismo y el ordenancismo, entre el horizonte y la pragmática, entre los proyectos intelectuales y la asunción del tránsito político. Las diferencias entre las intervenciones intelectuales y la política real, en resumidas cuentas. En segundo término, una lectura sobre las relaciones en tensión entre las derechas argentinas, ora de vínculo, ora de enfrentamiento, sin que ello rompiera las relaciones sociales que ligaban a sus referentes político-intelectuales. En el caso del libro de Petra, de su pauta se desprenden claves para repensar modos de enfocar idearios necesariamente internacionalizados como los que ocupan mis trabajos, al tiempo que permite complejizar ciertos diagnósticos sobre los universos antifascistas, sobre el cariz de los cruces de actores de izquierdas con el mundo liberal, sobre el peso de una mirada latinoamericanista no reductible al nacionalismo ni al reformismo, entre otros.

\section{UNA NOTA SOBRE TIEMPO, ESPACIO Y CATEgORÍAS}

Como señalé más arriba, mi trabajo sobre intelectuales liberal-conservadores abarca el período 1955-1983. Ello implica partir de las consecuencias del ascenso de estos intelectuales en el contexto del golpe de Estado setembrino y llegar hasta la transición democrática casi treinta años después. Sin embargo, el proceso de investigación debió incorporar, por un lado, una temporalidad abierta a la hora de articular una definición sobre el liberal-conservadurismo en sentido histórico-teórico que pudiera dar cuenta de los diversos procesos de origen, consolidación, vinculaciones y renovaciones de las cosmovisiones liberal y conservadora, en los que la pauta liberal-conservadora se articula antes como ideología asentada, doctrinaria y abierta a la renovación que como simple nexo de liberalismo y conservadurismo, a la vez que retoma una parte (sí que menor) de las pautas republicanas. Por otro lado, implicó considerar una temporalidad local capaz de inscribir el liberal-conservadurismo dentro de una historia de la tradición liberal argentina que pudiera dar cuenta del peso de una serie de hitos (la "línea Mayo-Caseros", el paradigma constitucional de 1853, la "generación del 80", entre los rescatados por los mismos actores) como de procesos (las problemáticas del "momento Centenario", la aparición del radicalismo y el peronismo, la larga inestabilidad política posterior a 1930), y que, yendo más allá de 1983, sin embargo se obligara a no considerar su objeto como una explicación instrumentalista para procesos posteriores, verbigracia el neoliberalismo de la década de 1990 o el giro argumental republicano posterior.

El posterior trabajo sobre Orden Cristiano tomó el tiempo de edición del quincenario, 1941-1948, pero consideraba el ciclo de ruptura del catolicismo argentino marcado por los quiebres de 1936, cuando el inicio de la guerra civil española y la visita al país del Jacques Maritain que acababa de editar Humanismo integral (que tan bien ha estudiado Zanca tras la huella de Olivier Compagnon) llevaron a diversas polémicas y enfrentamientos en el universo confesional (cf. Zanca, 2013a, 2014; Compagnon, 2003). Si bien en términos generales las trayectorias de los actores del quincenario antifascista católico perdieron densidad tras el cierre de la publicación, en mis trabajos busqué dar cuenta de una serie de ejes que inscribiera los años de la revista en una consideración mayor también luego de su cierre. La trama de desarrollo de la renovación del humanismo católico en la Argentina apareció en mis textos antes con la recepción por derecha que los intelectuales liberalconservadores dieron al personalismo desde 1955 que con el estudio de aquellos primeros impactos, que fui a analizar posteriormente. 
El actual proyecto sobre recepciones y usos del totalitarismo ha pasado por diversas fases. Primero me concentré en el ciclo 1936-1962. Se trató de un recorte que me permitió enfocarme en las relaciones entre el antifascismo de la década de 1930 y 1940, el antipopulismo de las de 1940 y 1950 y el anticomunismo que se perfila desde esa década hasta los primeros años de la siguiente. Este marco buscó encontrar las formas específicas de estas relaciones antes del impacto por el que la articulación entre diversas derechas amalgamó una lingua franca en torno a las claves de las doctrinas de la seguridad nacional. Actualmente, mi trabajo se recorta en el período 1945-1991, para enfocar el impacto de la Guerra Fría en las construcciones antitotalitarias en un marco temporal amplio. Me interesan aquí especialmente tres cuestiones, amén de las previas: las transformaciones en las posiciones político-intelectuales en el país a tono con las internacionales, marcadas por el proceso de la guerra fría; el impacto de los procesos de modernización en las relaciones entre política y cultura; y el cambio conceptual posterior a 1983.

En el sentido de las geografías políticas, mis trabajos abordan el espacio nacional por una doble pauta: el eje nacional permite analizar mostrando casos, debates y experiencias del mayor orden geográfico-estatal posible en un recorte que toma la dimensión país. Este enfoque permite ver, asimismo, una serie de relaciones de lo nacional con lo internacional en el plano ideológico, en el de las relaciones, en el de la tematización y las representaciones. En segundo término, en los tres casos que abordo se trató de experiencias de corte nacional en tanto las trayectorias de los actores, sus principales preocupaciones, y por ende sus intervenciones y sus polémicas, mantenían ese enfoque, mayormente desentendidos de lo provincial o lo municipal. Algunos de mis trabajos se han centrado directamente en las relaciones entre el plano nacional y el internacional, eje que, como destaqué, es de relevancia en mi enfoque. Tomo cuatro ejemplos, dos de cada una de mis investigaciones previas. Sobre los intelectuales liberal-conservadores, por ejemplo, publiqué un trabajo sobre el rol de la región latinoamericana en las intervenciones y relaciones de este espacio político-intelectual, al que suele enfocarse como primeramente preocupado por mirar a Europa y a los Estados Unidos, así como otro sobre los impactos que los sucesivos debates sobre el totalitarismo a escala internacional tuvieron para sus usos en el análisis de la realidad local, coescrito con Sergio Morresi, que fue un eje de partida para mi actual investigación (Vicente, 2016; Morresi y Vicente, 2017).

Sobre Orden Cristiano, por su parte, me interesa destacar un trabajo que aborda una historia del quincenario trazada entre una etapa marcada por la Segunda Guerra Mundial y el posterior ciclo de posguerra, que permite enfocar el momento peronista como una continuidad de los posicionamientos frente al conflicto mundial, y otro artículo que propone una lectura vinculante entre el grupo porteño y los humanistas chilenos de Politica y Espiritu (parte de la Falange Nacional donde se formará la Democracia Cristiana)y los uruguayos de Civilidad (pertenecientes a la Unión Cívica, base de la Democracia Cristiana de ese país), una mirada vincular entre grupos del Cono Sur que estaba ausente en las investigaciones previas (Vicente, 2015; Vicente, 2019a).

Sin embargo, considero que en los tres proyectos puede descenderse a la escala provincial o local para analizar una serie de cuestiones, como las organizaciones intelectuales, las publicaciones políticoculturales, sucesos puntuales e incluso figuras referenciadas en ámbitos sub-nacionales (hayan alcanzado o no la trascendencia nacional), lo cual tiene potencialidades específicas, como ha dejado en claro una serie de trabajos que han mostrado, por ejemplo, las pautas territoriales del liberal-conservadurismo en su organización de grupos y partidos, las condiciones locales de los católicos-democráticos en conexión con redes internacionales o las organizaciones antitotalitarias a ras de suelo (Gibson, 1996; Mauro, 2015 ; Bisso, 2013).

Si tiempo y espacio son dos marcos centrales para cualquier investigación, quisiera aquí considerar otra propuesta de las organizadoras de esta invitación, y abordar su pregunta respecto del lugar de categorías sobre clase/género/raza en mis investigaciones. Esta problemática, hoy central en la academia por el impacto de la "interseccionalidad" (especialmente en vínculo con los trabajos cruzados por una agenda de género) y por una relativa antropologización de las Ciencias Sociales, es de especial interés cuando se trabaja sobre grupos que, a priori, parecen no estar impactados por ítems de ese tipo. En mis trabajos, las categorías aparecen 
determinadas por dos sentidos básicos: el uso que mi enfoque les otorga y los presentes en los actores que abordo. Sobre aquella tríada de términos, el peso que ellos poseen en mis estudios es muy diferente. La categoría "clase" es problemática a la hora de enfocar a los intelectuales como conjunto (como se sabe, algunos analistas han propuesto la idea de "clase intelectual"), pero en el caso de los intelectuales liberal-conservadores es un término útil en diversos sentidos: por un lado, la procedencia de estos actores de sectores encumbrados de la sociedad los signa como parte de las clases altas, dato que se recoge por los apellidos que portan, sus biografías familiares y las sociabilidades que desarrollaron. Al mismo tiempo, la concepción lectura elitista de la sociedad que estos autores promovieron como uno de los ejes centrales de sus intervenciones presentó un carácter de clase evidenciado en una doble lectura: por un lado, una interpretación de las elites como elevadas por sobre el resto de la sociedad; por el otro, como un problema de dirección de la sociedad ante la ausencia de elites rectoras como las que habían primado hasta el advenimiento de la Ley Sáenz Peña. En sus trayectorias biográficas y en la dinámica elites-masas que marcó sus diagnósticos y propuestas, un sentido de clase apareció como determinante, al punto que la autopercepción intelectual acabó, en la década de los 70, operando como reformulación de la pauta elitista. También entre las firmas de Orden Cristiano encontramos una marcada procedencia de clase, cuestión que determinará las diferentes relaciones que este grupo tendrá con dos espacios del catolicismo democrático: los seguidores de Luigi Sturzo nucleados en I Popolari y los Pregoneros Social Cristianos. Mientras los antifascistas de la comunidad italiana, intentaron converger con los seguidores de Maritain pero acabaron considerándolos parte de las "oligarquías ciegas" que habían permitido el ascenso del fascismo en Italia y de su homólogo en la Argentina (en referencia al peronismo), los Pregoneros, en especial a través de Ambrosio Romero Carranza, lograron emprender proyectos en común con los miembros del quincenario. El mismo Romero Carranza actuó como un articulador entre el espacio del catolicismo democrático y los jóvenes intelectuales liberal-conservadores (Vicente, 2019b; Zanca, 2018).

Con respecto al caso del género, es notable la ausencia de intelectuales mujeres en el universo liberalconservador, lo cual se hace más peculiar si expandimos la mirada hacia el caso de Orden Cristiano y hacia el espacio antitotalitario, donde hubo clara presencia tanto de protagonistas femeninas como de ciertas reflexiones sobre sus lugares como intelectuales y militantes, e incluso una agenda feminista heterogénea. Una figura que puede cruzar los diversos espacios, como Victoria Ocampo (liberal y antitotalitaria con contactos con el universo del catolicismo democrático), es, sin embargo, más una muestra de la nula presencia entre la joven generación de intelectuales liberal-conservadores que ascienden desde 1955 tanto de mujeres como de una pregunta por la problemática de género (Sitman, 2003; González, 2018). Ello me permite plantear tanto una relación con otras derechas marcadas por la ausencia de mujeres entre sus figuras (aunque no por la pregunta por el rol de la mujer: como mostró tempranamente Sandra McGee Deutsch en 1999, este fue un eje de las derechas nacionalistas de la primera mitad del siglo XX) como abrir una pregunta: ¿no es esta ausencia una problemática característica de los espacios político-intelectuales centrales de la Argentina en gran parte del siglo XX, que a su vez replicó fenómenos socialmente más amplios?

Finalmente, la cuestión de la raza ha estado poco presente en mis trabajos pues casi no ha tenido presencia en las intervenciones de los diversos grupos intelectuales que me han ocupado. Una excepción, importante en términos de argumento pero que sin embargo no la quita de esa marginalidad, es la idea que circuló entre intelectuales liberal-conservadores sobre la relativa unidad racial argentina como una de las peculiaridades (incluso una "ventaja comparativa") de nuestra sociedad. Esta lectura hacía propios los diagnósticos más optimistas del liberalismo decimonónico a la vez que dejaba a un lado los lamentos de la etapa del Centenario. En uno de los trabajos que considero más interesantes en el universo liberal-conservador, La Argentina en su tiempo y el mundo, de Mariano Grondona, el ensayista lo proponía del siguiente modo:

Tradición no cristiana, reciente acceso a la independencia, razas de color: estos caracteres no económicos del 'tercer mundo' arrojan las primeras dudas sobre la ubicación de América latina. Porque estamos en el corazón de la tradición cristiana. Porque nuestra independencia tiene un siglo y medio de vida. Porque, en fin, la raza blanca ha dejado entre nosotros su impronta con variables grados de intensidad (1967, p. 215). 
Otra interpretación fuerte en este espacio es la que advertía sobre las lecturas racialistas como modalidad antidemocrática y totalitaria; por ejemplo, tal como la graficaba el jurista Germán Bidart Campos:

\footnotetext{
El estatismo y el totalitarismo proponen como fin del estado el bien y la grandeza del propio estado, en el cual se supone que se encarna la nación, la raza, el proletariado, etc. El estado interviene en todo, porque no se le escapa ningún ámbito de la vida personal y de la vida social. Diríamos que se introduce por todos los poros de la sociedad y que se infiltra en todas las actividades humanas. El hombre queda denigrado, y convertido en una herramienta del estado. 'Todo en el estado, nada fuera del estado, nada contra el estado, todo para el estado' (1973, p. 194).
}

La asunción por parte de los intelectuales liberal-conservadores de esos parámetros interpretativos colocaba el problema de las masas como eje de su diagnóstico general, problema que permitía que categorías como clase, género o raza se supeditaran al clivaje binario mayor, masas ante elites, y que se llegara, incluso, a la amenaza totalitaria, como en la cita previa. Ese diagnóstico, empero, presentaba en su interior una serie de definiciones que permite reverlas, en detalle muchas veces microscópico, a la luz de las cuestiones que se han planteado en la pregunta sobre el rol de esas categorías.

\section{UNA NOTA FINAL}

Los diversos grupos político-intelectuales sobre los que trabajé y trabajo han sido analizados (antes y después) por otros investigadores con especial atención en la pauta política. Sin dudas, la primacía de la política en estos conjuntos ha sido uno de los ejes de sus respectivas posiciones en los espacios políticointelectuales. Sin embargo, en mis indagaciones más recientes (sobre las cuales aún sigo trabajando) comencé a mover el foco hacia las problemáticas culturales, entendidas tanto en sentido amplio (lo cultural como manifestación social) como en un enfoque más restrictivo (las expresiones estético-artísticas). Ello tiene diversos significados en cada uno de los grupos y, estimo, es un punto central que compromete ciertos criterios de rigurosidad investigativa y narrativa. Considero a continuación los casos y luego expongo una lectura que extiende lo hasta aquí mencionado.

En los intelectuales liberal-conservadores, la primacía de la pauta política implicó cuatro cuestiones que considero centrales. En primer lugar, en este espacio predominó una lectura de lo cultural como una esfera separada de la política, cuya autonomía podía romperse sin embargo de modo directo (en el arte o las estéticas que tematizaban cuestiones políticas) e indirecto (al leer manifestaciones artístico-estéticas desde una crítica política). En segundo término, en los escasos momentos en que estos autores se acercaron a la cultura eligieron abordar manifestaciones estético-artísticas como las obras literarias o cinematográficas llamadas "de tesis" o "de ideas" antes que expresiones en las que el sentido estético fuese el central. Un tercer punto lo constituye la primacía que la tradición liberal tuvo en los años formativos de estos intelectuales, lo cual les otorgaba un suelo de sustento al tiempo que operaba como un claro límite quietista. Finalmente, un cuarto tema es la distancia y el desconocimiento con las culturas juveniles que tuvieron como eje la década de 1960, lo cual imprimió una relación peculiar de estos actores con su tiempo, tanto alejados de la fascinación por "lo nuevo" que caracterizó a muchas voces de la época como atentos, sin embargo, a ciertas lecturas en diálogo tenso con las transformaciones expresivas de la etapa.

En el caso de Orden Cristiano, el sentido de publicación de combate obturó en los estudios sobre la revista la importancia que diversas líneas culturales presentaron en sus páginas, como el interés por la narrativa literaria católica europea. Hay también en este ámbito una construcción de una voz propia y de un espacio de legitimidad como los que ha marcado Zanca (2013a, 2013b) y en ellos, además, aparecen claves para analizar el cada vez más progresivo espacio de libertad cultural del mundo católico con respecto a las pautas de la Iglesia y también de las concepciones otrora más cerradas del mundo de los fieles.

Sobre el espacio antitotalitario, aquí las investigaciones previas han mostrado el amplio abanico de instancias en el que las cuestiones políticas y las culturales se imbricaron: desde la literatura de cariz 
antifascista a las representaciones artísticas antiperonistas posteriores a 1955. Sin embargo, en el caso argentino poco sabemos de la producción estético-cultural anticomunista, excepto notables ejemplos en contrario. En las relaciones entre los diversos antitotalitarismos tenemos una serie de ejes para abordar a futuro. A modo de ejemplo, gran parte del bagaje de la novelística antitotalitaria tuvo efectos en las representaciones políticas del totalitarismo que realizaron los opositores a este, , en las que se podían conjugar tradiciones muy diversas: de la crítica de izquierda a la traición estalinista a la revolución de 1917 hasta la crítica a la estetización política motorizada por liberales, pasando por la atención que los católicos colocaron en la voz literaria de los grandes autores confesionales del siglo XX o la acusación, que cruzaba todos estos espacios, de que muchas revoluciones y revolucionarios no habían interpretado en su justeza la obra de Karl Marx (Morresi y Vicente, 2019).

Como señalé antes, presto especial atención a las relaciones entre las pautas teóricas, los desarrollos históricos, las recepciones y la representación de las ideologías en actores determinados. El paso de las preocupaciones de orden centralmente político hacia otras de cariz marcadamente cultural implica reposicionar los criterios de rigurosidad en al menos dos sentidos. En un sentido, entender que en los modos de captar la presencia de las pautas políticas y las culturales hay tanto una serie de puntos de encuentro (las manifestaciones político-culturales, las estéticas politizadas) como de separación (las expresiones que se reclaman autónomas en su tratamiento, los debates estético-artísticos en sentido técnico-expresivo), así como una zona gris de tensiones (las estéticas alusivas, las metáforas artísticas). En otro sentido, establecer una serie de marcos para el diálogo entre una bibliografía claramente centrada en las ideologías como lenguajes políticos con otra que hace eje en lo cultural como una serie de espacios que vinculan las producciones artístico-estéticas, las prácticas y representaciones sociales, las identidades no primeramente políticas, entre otras cuestiones de gran protagonismo.

Tengo como pauta básica de trabajo iniciar mis investigaciones con una serie de líneas centrales que formen la estructura básica de investigación, pero a partir de ese dato marco considero clave permitir que el objeto me imponga tanto su agenda como sus estructuras (es decir, el orden de preeminencia de sus temas) y modos expresivos (me interesa especialmente aprehender el tono de los intelectuales sobre los que trabajo). En ese sentido, busco darle al objeto una "libertad controlada", marcada por determinados límites que se ligan directamente en una serie de puntos con lo recién señalado. El primero de ellos es que el recorte temporal es en mis trabajos un eje que, sin embargo, me permite sobrepasarlo hacia atrás y hacia adelante para comprender historias más amplias y dotar de diversas capas de densidad a los temas que aparecen en cada proyecto, así como para permitir diálogos hacia afuera del tema central. En los recortes temporales, además, entiendo que puede descomponerse el corte general en momentos o procesos de menor duración que permiten entender peculiaridades determinadas dentro de un proceso de mayor extensión. El segundo punto es la aparición de temas que no hayan sido considerados en el diagrama de la investigación: es la cuestión que, personalmente, más disfruto en el estudio de un objeto, y en la que entiendo que se encuentra gran parte de la riqueza del proceso de investigación. La tercera cuestión es el cruce de los temas que aparecen en mis trabajos con los de otras investigaciones: más allá del obvio diálogo directo e indirecto, me interesa el trabajo de debate y de escritura con colegas que permite cruzar saberes y potenciar espacios temáticos. El cuarto ítem es lo que llamo la lectura microscópica; esta, a la hora de abordar mis objetos, la identifico centralmente con poder reconstruir temas que aparecen en posiciones sumamente marginales o expresadas por fuera de toda centralidad en la producción de los intelectuales que me han ocupado. Algo similar podría decirse de ciertos datos que en principio parecen colaterales en sus trayectorias. En ese sentido, abordar esas "historias mínimas" merece, sin embargo, dos consideraciones: por un lado, las entiendo como parte de líneas de investigación mayores, es decir, como obedientes a un proyecto de mayor volumen y relevancia; por el otro, considero necesaria una advertencia sobre el peligro inherente que acarrea no ya la hiperespecificidad temática (sobre la cual tengo, igualmente, reparos) sino la fascinación por el detalle mínimo que en lugar de un mapa grafica un simple punto. Para cerrar con la metáfora cartográfica, del otro lado de ese riesgo se encuentra el de aquella narración 
borgeana: dibujar un mapa insensato, que repita en tamaño el de la geografía representada. Por ello, subrayo que el camino que elijo parte de una lectura desde las ideologías, articulado sobre las agendas de los actores para, en un sentido, seguir reponiendo las características de esos trazos por los que preguntaba Mafalda, y mostrar cómo, para los que no participamos de él, un aparente garabato es en realidad una línea ideológica.

\section{ReFERENCIAS}

Bidart Campos, G. (1973). La historicidad del Hombre, del Derecho y del Estado. Buenos Aires: Manes.

Bisso, A. (2013). “Abajo con la tiranía pueblera y totalitaria”. Mechita o ciertas consideraciones en torno a un periódico pueblerino y ferroviario del antifascismo argentino. Prismas, 17, 221-225.

Compagnon, O. (2003). Jacques Maritain et l'Amérique du Sud: le modéle malgré lui. París: Presses universitaires du Septentrion.

Charle, C. (2009). El nacimiento de los intelectuales. Buenos Aires: Nueva Visión.

Dosse, F. (2007). La marcha de las ideas. Historia de los intelectuales, historia intelectual. Valencia: PUV.

Echeverría, O. (2009). Las voces del miedo. Los intelectuales autoritarios argentinos en las primeras décadas del siglo XX. Rosario: Prohistoria.

Gibson, E. (1996). Class and Conservative Parties: Argentina in Comparative Perspective. Baltimore: Johns Hopkins University.

González, M. S. (2018). Victoria Ocampo: escritura, poder y representaciones. Rosario: Prohistoria.

Grondona, M. (1967). La Argentina en su tiempo y en el mundo. Buenos Aires: Primera Plana.

Lahire, B. (2005). El trabajo sociológico de Pierre Bourdieu. Deudas y críticas. Buenos Aires: Siglo XXI.

Mauro, D. (2015). I Popolari en la Argentina. Luigi Sturzo y el antifascismo católico de entreguerras. Anuario del IEHS, $30,267-287$.

McGee Deutsch, S. (1999). Las derechas. La extrema derecha en la Argentina, el Brasil y Chile, 1890-1939. Bernal: UNQ.

Morresi, S. y Vicente, M. (2017). El enemigo íntimo: usos liberal-conservadores del totalitarismo en la Argentina entre dos peronismos (1955-1973). Quinto Sol, 21, 1-24.

Morresi, S. y Vicente, M. (2019). El combate fecundo: Aron frente a Marx y el izquierdismo. Cuestiones de Sociología, 20, 1-16.

Nallim, J. (2014). Transformación y crisis del liberalismo. Su desarrollo en la Argentina en el periodo 1930-1955. Buenos Aires: Gedisa.

Pasolini, R. (2013). Los marxistas liberales. Antifascismo y cultura comunista en la Argentina del siglo XX. Buenos Aires: Sudamericana.

Petra, A. (2018). Intelectuales y cultura comunista. Itinerarios, problemas y debates en la Argentina de posguerra. Buenos Aires: Fondo de Cultura Económica.

Rock, D. (1993). La Argentina autoritaria. Los nacionalistas, su historia y su influencia en la vida pública. Buenos Aires: Ariel.

Rosler, A. (2016). Razones públicas. Seis conceptos básicos sobre la república. Buenos Aires: Katz.

Sitman, R. (2003). Victoria Ocampo y Sur. Entre Europa y América. Buenos Aires: Lumen.

Skinner, Q. (2007). Lenguaje, politica e historia. Bernal: UNQ.

Spektorowski, A. (2011). Autoritarios y populistas: los origenes del fascismo en la Argentina. Buenos Aires: Lumiere.

Vicente, M. (2015). Orden Cristiano, entre las consecuencias de la Segunda Guerra Mundial y los inicios del peronismo: lecturas ante el mapa político de la posguerra. Anuario del IEHS, 30.

Vicente, M. (2016). América Latina según el liberal-conservadurismo argentino: entre la modernización, el panamericanismo y la Doctrina de Seguridad Nacional (1959-1973). En J. Bertonha y E. Bohoslavsky (coords.) 
(2016). Circule por la derecha. Percepciones, redes y contactos entre las derechas sudamericanas, 1917-1973. Los Polvorines: UNGS, pp. 247-266.

Vicente, M. (2019a). Entre publicaciones y partidos: grupos político-intelectuales en el catolicismo democrático del Cono Sur (Argentina, Chile y Uruguay en la década de 1940). En M. Castro y D. Mauro (eds.) (2020). Católicos y politica en América Latina (primera mitad del siglo XX). Caseros: UNTREF, pp. 225-249.

Vicente, M. (2019b). El grupo de Orden Cristiano ante el peronismo. Una trayectoria grupal entre la renovación humanista, el antifascismo católico y el horizonte demócrata-cristiano. En C. Barry y M. Lida. Historias de vida del catolicismo peronista. Caseros, UNTREF (en prensa).

Zanca, J. (2013a). Cristianos antifascistas. Conflictos en la cultura católica argentina. Buenos Aires: Siglo XXI.

Zanca, J. (2013b). “¿Se ha hecho Dios fascista?” Orden Cristiano y los intelectuales católicos argentinos durante la II Guerra Mundial. En C. Rodríguez y G. Zanotto (comps.). Catolicismo e sociabilidade intelectual na America Latina. Cuiabá: Editora da Universidade Federal da Matto Grosso, pp. 48-65.

Zanca, J. (2014). Jacques Maritain en Argentina, la cita envenenada. En P. Bruno (coord..). Visitas culturales. Argentina, 1890-1936. Buenos Aires: Biblos, pp. 204-228.

Zanca, J. (2018). Los humanistas universitarios. Historia y memoria (1950-1966). Buenos Aires: EUDEBA. 